\title{
The Impact of Detailed Snow Physics on the Simulation of Snow Cover and Subsurface Thermodynamics at Continental Scales
}

\author{
Marc Stieglitz' ${ }^{1}$ Agnes Ducharne ${ }^{2}$, Randy Koster ${ }^{3}$, Max Suarez $^{3}$ \\ 'Lamont Doherty Earth Observatory, Columbia University, Palisades, NY \\ 10964 \\ UMR Sisyphe, Université Pierre et Marie Curie Boite 123, 75252 \\ Paris Cedex 05, France \\ ${ }^{3}$ Hydrologic Sciences Branch, Laboratory for Hydrospheric Processes, \\ NASA/Goddard Space Flight Center, Greenbelt, MD
}

For Submission to

Journal of Hydrometeorology

27 April 2000 


\begin{abstract}
The three-layer snow model of Lynch Stieglitz et al. [1994] is coupled to the global catchment-based Land Surface Model (LSM) of the NASA Seasonal to Interannual Prediction Project (NSIPP) project, and the combined models are used to simulate the growth and ablation of snow cover over the North American continent for the period 1987-1988. The various snow processes included in the three-layer model, such as snow melting and re-freezing, dynamic changes in snow density, and snow insulating properties, are shown (through a comparison with the corresponding simulation using a much simpler snow model) to lead to an improved simulation of ground thermodynamics on the continental scale.
\end{abstract}




\section{Background}

In the northern hemisphere, the mean monthly land area covered by snow ranges from $7 \%$ to $40 \%$ during the annual cycle, making snow cover the most rapidly varying large scale surface feature on earth [Hall et al., 1994]. As such, the spatial structure of snow cover can have an important impact on atmospheric circulation. Snow covered landscapes adjacent to bare soil regions have been found to produce mesoscale wind circulations [Johnson et al., 1984]. Historical data analysis has suggested that snow cover extent influences the development of the Asian monsoons in that an earlier snowmelt is associated with greater summer land heating and a stronger monsoonal season. [Dey and Bhanukumar, 1983; Hahn and Shukla, 1976; Kripalani et al., 1996; Ropelewski et al., 1984]. More recently, Kumar et al. [1999] have shown that the historical teleconnection between Eurasian snow cover and the Indian Monsoon may have broken down under the influence of a long term warming trend. Cohen and Entekhabi [1999] have suggested that anomalies in Eurasian snow cover leads to an expansion of the Siberian high over northern latitudes and through a displacement of the Icelandic low, affects the North Atlantic Oscillation. In turn, this results in colder surface air temperatures in eastern North America and Western Europe as well as wetter conditions in Southern Europe and the Mediterranean. Hence, accurate long-term forecasts in a fully-coupled climate system can be strongly dependent on an accurate simulation of the snow covered area, snow water equivalent, and snow depth.

As a medium-term water store, snow plays an important role in springtime runoff generation and flood production. In many northern latitude regions, as well as regions with high relief, spring meltwater derived from the winter snow pack represents the greatest source for the yearly ground moisture budget [Aguado, 1985]. Further, at high 
latitudes the magnitude and timing of spring snowmelt water delivered to the Arctic Ocean affects the stability of the ocean's surface layer, and it thereby affects ocean circulation and seasonal sea ice formation [Mysak and Venegas, 1998].

Since a snowpack is thermally insulating and limits the otherwise efficient heat exchange between the ground and the atmosphere, it controls the evolution of wintertime ground temperatures. Through freeze-thaw activity, this control over the evolution of ground temperatures influences the downslope redistribution of shallow ground water, surface runoff, and evapotranspiration. Ground temperatures in turn also influence soil microbial activity and the associate fluxes of $\mathrm{CO}_{2}$ and $\mathrm{CH}_{4}$ to the atmosphere. Both $\mathrm{CO}_{2}$ flux tower measurements and modeling studies show that a longer growing season, associated with a shorter snow season, is positively correlated with a net annual carbon sequestration [Goulden et al., 1996; Goulden et al., 1998; Stieglitz et al., in review]. Further, due to the greenhouse capacity of trace gases, the interaction between ground freezing, vegetation and release of soil carbon as $\mathrm{CO}_{2}$ or $\mathrm{CH}_{4}$ can also lead to climate feedbacks that act on longer time scales.

As a practical demonstration of the impact that snow insulation has on the evolution of ground temperatures, Figure 1 shows air and ground temperatures at two sites for which seasonal snow cover is significant; Sleeers River, Vermont, and Imnavait Creek, Alaksa. During the summer months, when the snowpack is non-existent, the air and surface ground temperature track each other with only a small offset in temperature. However, once the snow begins to accumulate, the relatively warm ground is insulated from the cold atmosphere and ground temperatures remains warm throughout the season. In effect, the pack prevents the escaping of heat from the warm ground to the atmosphere, 
or conversely, damps out the cold wintertime temperature signal in the snowpack well before it reaches the ground.

Despite the acknowledged role that the snow cover plays in regulating the earth's global water and energy budgets, most land surface models (LSMs) intended for use in exploring the above mentioned feedbacks (i.e., coupled with atmospheric circulation models, ocean, and sea ice models) are inadequate for modeling high latitude processes. Previous work on the development of land surface schemes has primarily focused on developing multiple layer soil column models and improving canopy processes, with little attention paid to high latitude processes, and more specifically, to snow physics or permafrost dynamics. As a step toward addressing this deficiency, the three-layer snow model of Lynch Stieglitz [1994]has recently been coupled to the (NASA Seasonal to Interannual Prediction Project) NSIPP catchment based LSM. We demonstrate in this paper that through a sufficient representation of snow processes, we significantly improve the LSM's simulation of high latitude processes, particularly the evolution of subsurface ground temperatures.

\section{$2 \quad$ Modeling snow cover}

While sophisticated multi-layer snow models have been developed and successfully applied at the local scale [Davis et al., 1995; Hardy et al., 1998; Jordan, 1995], the treatment of snow processes, especially those used within general circulation models (GCMs), have been relatively simple. Some models consider the winter snow pack only as a store of moisture [Abramopoulos et al., 1988; Bonan, 1996; Koster and Suarez, 1996], while others blur the distinction between the snow and the ground surface altogether by envisioning a composite soil and snow layer LDickinson et al., 1993; 
Pitman et al., 1991]. Still others do distinguish between separate snow and ground layers, yet represent the entire pack with a single snow layer regardless of the actual pack depth [Slater et al., 1998; Verseghy, 1991]. However, as demonstrated at small experimental catchments [Lynch-Stieglitz, 1994; Yang et al., 1997], such a simple representation of snow and cold season processes can lead to a corruption of surface energy fluxes and a degradation of the snow insulation between the cold atmosphere and the warm ground. In turn, this compromises the seasonal development of ground freezethaw processes and the associated hydrologic processes such as runoff, ground water movement, infiltration and evapotranspiration. Figure 2a shows model-data surface radiation temperatures at the Sleepers River NOAA-ARS snow research station, located in Northern Vermont. In this region of the U.S., snow cover, which is appreciable from 7 December to 5 May, limits the heat flux from the ground to such an extent that below 7.5 $\mathrm{cm}$ the ground is never frozen and by the end of the spring melt the ground is entirely thawed. Hourly hydro-meteorological data were used to force an LSM that treated snow cover as nothing more than a store of water and energy. As snow accumulates and its associated heat capacity increases, the snow surface skin temperature can no longer adequately responds to rapid swings in the atmospheric temperature. On a diurnal basis, this leads to a snow skin temperature that is too warm, resulting in artificially large heat loss due to radiative cooling. In turn, this cooling of the snow surface is compensated for by an upward transport of heat from warm deep ground layers. Eventually, the soil column unrealistically cools and freezes. Further, this freezing (to a depth of $2 \mathrm{~m}$ ) represents such a large heat loss from the ground system that deeper layers do not unfreeze until late summer, obviously affecting the normal seasonal evolution of 
hydrologic processes. It is this lack of sufficient treatment of the snowpack physics, specifically, snow insulation that is responsible for both the loss of ground heat and the inconsistent heat fluxes.

Recently, sophisticated snow physics have been included in some LSMs and demonstrate a clear improvement in the overall simulation of the hydrologic cycle at the catchment scale [Loth and Graf, 1998a; Loth and Graf, 1998b; Loth et al., 1993; Stieglitz et al., 1997; Yang et al., 1997]. Typically, these multi-layer snow schemes explicitly model the heat and mass (water) transport within the pack. Radiation conditions determine the surface energy fluxes, and the heat flow within the pack is accomplished via linear diffusion along the thermal gradient. Meltwater generated within a given layer can drain to a lower layer, where it will refreeze, remain in the layer in the liquid state, or pass through.

We now present the coupling of the Lynch-Stieglitz [1994] three-layer snow model to the NSIPP catchment based LSM and validation over North America for the 1987-1988 snow season. We will demonstrate, via comparisons with corresponding simulations that use the much simpler Mosaic snow scheme [Koster and Suarez, 1996], that the more sophisticated model can overcome the deficiencies outlined above at the continental scale.

\subsection{Coupling a three-layer snow model to the NSIPP catchment based LSM}

\subsubsection{A three-layer snow model:}

This three-layer snow model accounts for snow melting and refreezing, dynamic changes in snow density, snow insulating properties, and other physics relevant to the growth and ablation of the snowpack. The boundaries of the snowpack move up and 
down under the influence of snowfall, mechanical and wet compaction, condensation, sublimation, etc. We now discuss these processes in turn.

The snowpack is modeled with three snow layers. Three variables are needed to completely describe the system: layer thickness $\left(Z_{i}\right)$, water equivalent $\left(W_{i}\right)$, and heat content $\left(H_{i}\right)$. Heat and mass (water) flow within the pack is explicitly modeled. Radiation conditions, as well as the evolution of the snow albedo determine the surface energy fluxes. Heat flow within the pack is accomplished solely via linear diffusion along the thermal gradient. Each snow layer is characterized by a volumetric water holding capacity. As such, meltwater generated in a layer will remain in the layer if the liquid water content of the layer is less than the layer holding capacity. Otherwise, it will flow down to a lower layer where it will refreeze in the layer, remain in the layer in the liquid state, or pass through. Two independent processes govern densification of the pack. A simple parameterization is used to describe mechanical compaction, or compaction due to the weight of the overburden [Kojima, 1967; Pitman et al., 1991], and a separate densification is accomplished via the melting-re-freezing process. Snowfall, evaporation, sublimation, and condensation represent sources and sinks of mass and heat into the uppermost snow layer. Finally, resolution requirements dictate that in order to capture reasonably the diurnal range in the surface radiation temperature, the upper surface layer can be no greater than the thermal damping depth of snow, approximately, 6- $10 \mathrm{~cm}$. This requires that at every time step a simple mass wise redistribution of heat and water contents are performed among the three model layers.

The snowpack albedo is explicitly modeled. For computational simplicity we appropriately modify the formulation of Hansen et al. [1983], in which snowpack albedo 
is parameterized as a function of snow surface aging, to instead to be a function of the density of the snow surface layer.

Results at the Sleepers River watershed in Vermont $\left(8.4 \mathrm{~km}^{2}\right)$ demonstrate the superiority of using this three-layer model instead of the simpler snow formulations discussed above. Not only are the radiation temperatures of the ground and snow surface now adequately modeled, but all the features of snowpack ripening that characterize pack growth/ablation are also well simulated (Figures 2b, 3) [Lynch-Stieglitz, 1994].

\subsubsection{The NSIPP catchment based LSM}

The catchment-based LSM was developed to overcome a critical deficiency in standard GCM-based LSMs, namely, the neglect of an explicit treatment for spatial variability in soil moisture. Standard LSMs employ a one-dimensional treatment of subsurface moisture transport and surface moisture and energy fluxes that effectively assumes homogeneous soil moisture conditions across areas spanning hundreds of kilometers. Much recent development work by various groups has focused on improving the 1-D representation itself, incorporating, for example, improved treatments of transpiration resistance and even carbon budget models into the evaporation calculation. Relatively little attention has been given to the spatial heterogeneity issue. This is unfortunate given that this heterogeneity can have a strong impact on surface energy and water budgets.

The strategy [Koster et al., in review] calls for the partitioning of the continental surface into a mosaic of hydrologic catchments, delineated through analysis of surface elevation data. Thus, the effective "grid" used for the land surface is not specified by the overlying atmospheric grid. Within each catchment, the variability of soil moisture is 
related to characteristics of the topography and to three bulk soil moisture variables through a TOPMODEL-type formulation of catchment processes [Beven and Kirkby, 1979]. Many of the ideas underlying the strategy are culled from works of Beven and Kirkby [1979], Famiglietti and Wood [1991], Sivapalan et al. [1987], Stieglitz et al. [1997], among others.

A particularly unique aspect of the catchment model is the separation of the catchment into three subareas, each representing a distinct hydrological regime: one in which the surface is saturated, one in which the surface is unsaturated but transpiration proceeds without water stress, and one in which transpiration is stressed. Because these subareas are tied to the dynamically varying moisture variables in the catchment, their sizes vary with time. Key to the modeling strategy is the application of different formulations of evapotranspiration and runoff in each subarea to reflect the fundamentally different physical mechanisms controlling these fluxes in the three regions. This is a far more physically consistent approach than is possible with traditional one-dimensional LSMs.

Transpiration and other surface energy balance calculations proceed using established and tested code from a standard "SVAT-type" vegetation model [Koster and Suarez, 1996; Koster and Suarez, 1992] that includes bare soil evaporation and canopy interception loss. The SVAT code used for one-dimensional energy balance calculations is applied over each of the three identified moisture regimes. Each moisture sub-region maintains its own prognostic surface temperature; no "smoothing out" of this temperature is performed at the end of a time step. This allows the valley bottoms, where more evapotranspiration occurs, to remain consistently cooler than the drier uplands. 
Of particular relevance here is the treatment of ground thermodynamics. Although each of the three sub-regions maintains its own surface/canopy temperature, temperatures for deep soil levels are assumed to be spatially homogeneous. The net heat flux from model surface soil layer to the layer just below is computed by weighting the individual heat flux from each moisture sub-region by its respective area and then summing together the three weighted fluxes. Heat transport within the soil column is governed by linear diffusion along the thermal gradient. Layer thicknesses follow a geometric series. The top layer's thickness is taken to be $5 \mathrm{~cm}$ to allow us to capture the diurnal range in the surface radiation temperature. To be compatible with the assumption that a zero heat flux condition applies at the bottom boundary of the deepest model layer, the ground profile extends to a depth of $10 \mathrm{~m}$, approximately three times the seasonal damping depth for typical soils

The model has been tested offline over the Red-Arkansas basin, using forcing established for the PILPS 2c intercomparison study [Wood et al., 1998]. With a minimal amount of calibration, the catchment model reproduces the observed surface fluxes in the basin as well as the inter-annual variability with high accuracy [Ducharne et al., in review].

\subsubsection{Coupling the snow model to the catchment based LSM}

The coupling of the snow model to the catchment framework necessitated some modifications to the above described snow scheme. In particular, we now ensure a smooth transition between snow-free and snow-covered conditions in order to capture the gradual growth of a snowpack's spatial extent and to avoid abrupt (discontinuous) changes in the surface energy balance calculations. The approach used is straightforward. 
We assume a minimum local snow water equivalent, $S W E_{\min }$, of $13 \mathrm{~mm}$. If a given volume of snow falls on a snow-free catchment, that volume is spread uniformly over a fraction of the catchment so that the local water equivalent at any snow-covered point is $S W E_{\text {min }}$. Thus, if the snow falling on a snow-free catchment during a timestep has a total water equivalent volume, $V_{s}$, and if the area of the catchment is $A$, then the-snow-covered area, $A_{s}$, is taken to be $V /\left(S W E_{\min }\right)$. The snow-covered areal fraction, $A_{s} / A$, increases as more snow falls until it reaches 1 , at which time the local snow water equivalents across the catchment start increasing uniformly. When the fractional coverage is less than one, the snow model is represented with a single snow layer, whereas three model layers are used when the snow coverage is complete [Lynch-Stieglitz, 1994]. The transition between the single layer and three layer representations involves a simple conservative redistribution of layer heat and water contents. Surface energy calculations are performed separately over the snow free and snow covered areas. With $13 \mathrm{~mm}$ as the value for $S W E_{\min }$ we can resolve the diurnal surface temperature signal and at the same time produce a stable solution with a 20 -minute timestep.

\subsection{A simpler scheme: the old Mosiac snow model}

One of the goals of this paper is to demonstrate that the physics incorporated into the three layer snow model leads to an improved simulation of snow processes at the continental scale. We thus examine the behavior of a less sophisticated model in conjunction with that of the new model.

The less sophisticated model chosen for the comparison is the snow module of the Mosaic land surface scheme (Koster and Suarez, 1996). This model tracks the growth and ablation of snow with a single moisture reservoir. Compaction, liquid water storage, 
refreezing, and other such processes within the snowpack are ignored; nevertheless, conservation of snow water is strictly maintained. The entire snowpack is assumed to have the same temperature as the underlying surface soil, and a single energy balance is calculated for the combined snow/surface soil system. Snow, of course, affects this calculation by imposing its own albedo (which accounts for subgrid snow coverage but not for snow aging) and by providing an energy sink during snowmelt.

The Mosaic land surface scheme has been used in numerous GCM studies, and its snow module has proven robust. Foster et al. [1996] present a comparison of observed continental-scale snowcover with the snowcover generated by several GCMs, including the GCM coupled to the Mosaic scheme. Although the Mosaic snow scheme produced a reasonable simulation of snowcover in this study, it tended to underestimate snow water equivalent. Model errors in this study, however, also reflect errors in the GCM's simulated precipitation and temperature forcing.

\section{Validation over North America}

At the continental scale we can evaluate the ability of the model to simulate spatial coverage of snow, as well as snow amounts, over large areas. To this end, the ISLSCP Initiative 1 CD-ROM [Sellers et al., 1996] data were used to drive the model over North America for the period 1987 - 1988. Northern Hemisphere EASE-Grid Weekly Snow Cover data set is used to evaluate simulated snow coverage [NSIDC, 1996]. Further using the NSIDC digital permafrost maps [Zhang et al., 1999] we can evaluate the impact that snow insulation has on the evolution of ground temperatures; specifically, the evolution of the southerly extent of the continental permafrost front. 
For the present analysis, the coupled catchment/snow model was driven over North America (partitioned into about 5000 catchments based on the USGS EROS Data Center's GTOPO30 data [Verdin and Verdin, 1999], using hourly atmospheric forcing derived from the ISLSCP Initiative 1 CD-ROM [Sellers et al., 1996]. This dataset covers the two-year period 1987-1988, and thus we were able to simulate in full the growth and ablation of snowpack for the winter of 87-88. Spin up of model variables was achieved by cycling the model through the two years of forcing data at least five times, with model diagnostics saved only during the final cycle.

The same spin up process was then repeated using the catchment model coupled to the snow scheme from the Mosaic LSM (see section 3.2 above). For logistical reasons, the version of the catchment model used here was older and somewhat inferior to that which was used with the three-layer snow scheme, with differences mainly in the representation of soil/catchment hydrology. However, since the present analysis focuses on snow dynamics and subsurface thermodynamics, and since both versions of the catchment model employed the same subsurface heat diffusion algorithm, the comparison should be quite valid. In essence, the differences induced by using two different versions of the catchment model are confined to snow-free periods.

Figures 4-5 show the spatial evolution of snow coverage over North America for the 1987-1988 snow season. Both the old Mosaic snow model and the new scheme capture this evolution fairly well. Considering that the major driver for both schemes is the total atmospheric radiation, air temperature, and precipitation, this result is somewhat to be expected. When atmospheric conditions favor snowfall, snow cover accumulates, and when conditions shift in favor of melting, the pack ablates. The ground-snow heat 
flux has significantly less impact on pack growth and ablation than the snow-atmosphere flux. However, as demonstrated in Lynch-Stieglitz [1994], this does not imply that the surface radiation temperatures evolve similarly with both models. Therefore, when the land-atmosphere feedbacks are possible (i.e., in coupled land-atmosphere runs), the spatial evolution of the snowpack may evolve differently for the two schemes over the course of a snow season.

To better understand the control that snow insulation has over the evolution of the ground thermal processes, Figures 6-8 show ground temperatures with depth at three locations $(54 \mathrm{~N}-99 \mathrm{~W}, 61 \mathrm{~N}-99 \mathrm{~W}, 68 \mathrm{~N}-159 \mathrm{~W})$ for the $1987-1988$ snow season. The length of the snow season increases from 4 months at $51 \mathrm{~N}$ to just under 10 months at $68 \mathrm{~N}$. In all cases, the impact of snow insulation is clear. In the old scheme the ground and atmosphere are effectively in direct contact, regardless of the intervening snowpack, and with the onset of winter the soil is quickly depleted of heat content. With the new snow scheme, on the other hand, the ground heat reservoir, which has been gaining energy throughout the warm summer months, is effectively cut off from the cold atmosphere once snow cover accumulates, and this minimizes heat loss. Comparing model-generated results at $61 \mathrm{~N}$ with data taken at the nearby Boreas sites [Levine and Knox, 1997; Pauwels and Wood, 1999], demonstrates that mid-winter temperatures in the old scheme are too cold by approximately $15-20 \mathrm{deg}$. C, while the new scheme evolves ground temperatures in close agreement to site data. It is interesting to note however, that except for differences in the deep model temperatures, the profiles are remarkably similar by the end of the summer; i.e., the soil heat memory is only on the order of several months. In any case, the impact of extreme ground freezing with depth in the mid-winter using the 
old scheme can have profound implications for both hydrologic and biologic processes, as well as for the proper simulation of the surface energy fluxes. For example, the extremely cold mid-winter ground temperatures will effectively shut off microbial respiration, which have been shown to operate at temperatures as low as $-7 \mathrm{deg}$. C. As demonstrated by Oechel and others [Oechel et al., 1997; Zimov et al., 1996; Zimov et al., 1993], this winter respiration can account for as much as $30 \%$ of the annual soil respiration at high latitudes.

Figure 9 shows the that spatial difference in temperatures for the deepest soil layer between the new and old snow scheme after the model is spun up can be as much as 9 deg. C. The reason for this is as follows. As snow accumulates, the ground under the new snow model is insulated from the cold winter air temperatures, and as a result, evolves a deep ground temperature which is considerably higher than the overlying mean annual air temperature. On the other hand, the old scheme, which has no representation of snow insulation, continually loses heat to the atmosphere until equilibrium is reached, at which point the deep model temperature is close to the long-term air temperature overlying a given region. Further, the general trend is such that the deep soil temperature difference between the models increase with latitude, corresponding to a longer snow season with latitude, and therefore a longer period in which winter snow insulation is operating in the new model. For similar reasons, regions showing an especially large difference, east of the Hudson Bay and north of the Gulf of Alaska, are regions where the new snow scheme predicts earlier snow accumulation and later melt than the old snow scheme (see Figure 4). 
The fact that the soil heat content using the old snow scheme is less than that of the new snow scheme, especially at lower latitudes, is reflected in the permafrost maps in Figure 10. Here we consider a catchment to be within a permafrost region and thereby shaded gray if the deepest model layer within that catchment is frozen throughout the two-year simulation. With few exceptions, the permafrost boundary generated by the new scheme appears highly accurate - the solid line in the figure refers to the observed permafrost line corresponding to $50 \%$ permafrost coverage whereas the dashed line corresponds to $10 \%$ permafrost coverage [Zhang et al., 1999]. Similar success, however, is not found with the old scheme, for which the southerly extent of permafrost front extends from Washington State in the west to Montreal, Canada, in the east. This comparison indicates that the three-layer model, originally developed and validated at small experimental catchments [Lynch-Stieglitz, 1994; Stieglitz et al., 1999] does indeed capture the important snow processes which control the growth and the ablation of continental-scale snowpack and its snow insulation capabilities

\section{$4 \quad$ Future model developments}

As stated earlier, to avoid abrupt discontinuities in the surface energy balance calculations, we account for sub-grid scale variability in snow cover when the pack is thin. However, even when snow cover is substantial, snow heterogeneity can be significant [Liston, 1986; Liston and Sturm, 1998]. Gradients in elevation, differences in aspect, and the interactions between wind, topography and vegetation will all result in snow cover heterogeneity. We currently ignore these effects and their influence on the surface energy fluxes. 
To account for elevation effects in regions of high relief, a temperature lapse rate can be used along with binned elevation bands to distribute snow cover and snow melt throughout the landscape [Bowling and Lettenmaier, 1998]. To account for the effects that wind, vegetation, and topography have on the distribution of snow cover, the work of Liston and Sturm [1998] can be adapted to our modeling framework. While their spatially explicit model is not directly compatible with the statistical treatment of topography presented here, the empirical equations governing wind blown snow can be used to treat snow distribution in much the same way we currently treat soil moisture heterogeneity; through a statistical representation in which valleys are regions of snow accumulation and uplands are regions of snow ablation. Hartman et al. [1999] recently applied such a procedure, albeit without explicitly including for the effects of wind blown snow, and had success in improving snowmelt discharge.

\section{Conclusions}

General Circulation Model experiments predict that $\mathrm{CO}_{2}$-induced global warming will be greatest at high northern latitudes. Associated with such rising temperatures would be increased precipitation and earlier snowmelt [IPCC, 1995]. With this in mind, researchers are attempting to answer a number of key questions: Will changes in snow cover extent and amount affect regional and global climate via changes in the surface energy balance? Will climate change augment plant growth and thus increase the uptake of $\mathrm{CO}_{2}$ from the atmosphere? If Arctic rivers deliver less freshwater to the Arctic Ocean due to enhanced evapotranspiration, what will be the impact on river ecology, ocean shelf dynamics, surface ocean stability, and sea ice formation? If soils become warmer, will the increased microbial activity release carbon stored in the soil? Will warmer 
temperatures increase the production of methane, another greenhouse gas, in regions where wetlands expand? To answer these questions on an global basis, there is a need for a new generation of computationally efficient models that can adequately represent snow processes.

We have coupled the snow model of Lynch Stieglitz [1994] to the global catchment-based LSM of the NASA NSIPP project. This three-layer snow model accounts for snow melting and refreezing, dynamic changes in snow density, snow insulating properties, and other physics relevant to the growth and ablation of the snowpack. Validating with 1987-1988 ISLSCP data sets at over the 5000 catchments representing North America indicates that the model is capable of simulating the spatial coverage of snow. More importantly, the model's treatment of the insulation properties of snow cover leads to an accurate simulation of the permafrost front, relative to the NSIDC digital permafrost map. Finally, the successful larger-scale application of the model for North America suggests that the global application of the model is within reach, and more specifically, that application at high latitudes will be successful.

\section{Acknowledgements:}

This research is a contribution to the NASA Seasonal-to-Interannual Prediction Project at Goddard Space Flight Center, supported by NASA's Global Modeling and Analysis Program under RTOP 622-24-47. This work was also supported by NSF grants from the division of Environmental Biology (Arctic LTER Project), from the office of Polar Programs (Arctic Natural Sciences, Arctic Systems Science (Land-Atmosphere-IceInteractions)), These data, Northern Hemisphere EASE-Grid Weekly Snow Cover and Sea Ice Extent, were obtained from the EOSDIS NSIDC Distributed Active Archive 
Center (NSIDC DAAC), University of Colorado at Boulder. Finally, we would like to thank T. Zhang at the Cooperative Institute for Research in Environmental Sciences at the University of Colorado for providing us with the digital permafrost map 


\section{References}

Abramopoulos, F., C. Rosenzweig, and B. Choudhury, Improved ground hydrology calculations for global climate models (GCMs):Soil water movement and evapotranspiration, J. Climate, 1, 921-941, 1988.

Aguado, E., Radiation balances of melting snow covers at an open site in the Central Sierra Nevada, California, Water Resour. Reasearch, 21, 1649-1654, 1985.

Beven, K.J., and M.J. Kirkby, A physically-based variable contributing area model of basin hydrology, Hydrol. Sci. J, 24 (1), 43-69, 1979.

Bonan, G.B., A Land Surface Model (LSM Version 1.0) For Ecological, Hydrological. and Atmospheric Studies: Technical Description and User's Guide, pp. 150, NCAR, Boulder, CO, 1996.

Bowling, L.C., and D.P. Lettenmaier, A Macroscale Hydrological Model for the Arctic Basin, in FALL AGU, San Fransisco, 1998.

Cohen, J., and D. Entekhabi, Eurasian snow cover variability and northern hemisphere climate predictability, Geophysical Research Letters, 26, 345-348, 1999.

Davis, R.E., J.C. McKenzie, and R. Jordan, Distributed snow process modelling: An image processing approach, Hydrological Processes, 9 (8), 865-875, 1995.

Dey, B., and O.S.R.U. Bhanukumar, Himalyan winter snow cover area and summer monsoon rainfall over India, J. Geophys., Res., 88, 5471-5474, 1983. 
Dickinson, R.E., A. Henderson-Sellers, P.J. Kenndy, and M.F. Wilson, Biosphere Atmosphere Transfer Scheme (BATS) Version le as coupled to the NCAR Community Climate Model, pp. 72, NCAR, 1993.

Ducharne, A., R.D. Koster, M.J. Suarez, M. Stieglitz, and P. Kumar, A catchment-based approach to modeling land surface processes. Part II: Parameter estimation and model demonstration, JGR, in review.

Famiglietti, J.S., and E.F. Wood, Evapotranspiration and Runoff From Large Land Areas - Land Surface Hydrology For Atmospheric General-Circulation Models, Surveys in Geophysics, 12 (1-3), 179-204, 1991.

Foster, J., G. Liston, R. Koster, R. Essery, H. Behr, L. Dumenil, D. Verseghy, S. Thompson, D. Pollard, and J. Cohen, Snow cover and snow mass intercomparisons of general circulation models and remotely sensed datasets, $J$. Climate, 9, 409-426, 1996.

Foster Jr., D.J., and R.D. Davy, Global snow depth climatology, pp. 43, USAF Environmental Technical Applications Center, Scott Air Force Base, Illinois, December, 1988.

Goulden, M.L., J.W. Munger, S.M. Fan, B.C. Daube, and S.C. Wofsy, Exchange of carbon dioxide by a deciduous forest: Response to interannual climate variability, Science, 271 (5255), 1576-1578, 1996.

Goulden, M.L., S.C. Wofsy, J.W. Harden, S.E. Trumbore, P.M. Crill, S.T. Gower, T. Fries, B.C. Daube, S.M. Fan, D.J. Sutton, A. Bazzaz, and J.W. Munger, Sensitivity of boreal forest carbon balance to soil thaw, Science, 279 (5348), 214 $217,1998$. 
Hahn, D.G., and J. Shukla, An apparent relationship between the Eurasian snow cover and Indian monsoon rainfall, J. Atmos. Sci, 33, 2461-2462, 1976., 1976.

Hall, D.K., D.B. Fagre, F. Klasner, G. Linebaugh, and G.E. Liston, Analysis of Ers-1 Synthetic-Aperture-Radar Data of Frozen Lakes in Northern Montana and Implications For Climate Studies, Journal of Geophysical Research-Oceans, 99 (C11), 22473-22482, 1994.

Hansen, J.E., G. Russel, D. Rind, P.H. Stone, A.A. Lacis, S. Lebedeff, R. Ruedy, and L. Travis, Efficient three dimensional global models for climate studies: Models I and II, Mon. Wea. Rev., 111, 609-662, 1983.

Hardy, J.P., R.E. Davis, R. Jordan, W. Ni, and C.E. Woodcock, Snow ablation modelling in a mature aspen stand of the boreal forest, Hydrological Processes, 12 (10-11), 1763-1778, 1998.

Hartman, M.D., J.S. Baron, R.B. Lammers, D.W. Cline, L.E. Band, G.E. Liston, and C. Tague, Simulations of snow distribution and hydrology in a mountain basin, Water Resources Research, 35 (5), 1587-1603, 1999.

IPCC, Climate Change 1995: The Science of Climate Change, Cambridge University Press, Cambridge, 1995.

Johnson, R.H., G.S. Young, and J.J. Toth, Mesoscale weather effects of variable snow cover over northeast Colorado, Mon. Wea. Rev., 112, 1141-1152, 1984.

Jordan, R., Effects of Capillary Discontinuities On Water-Flow and Water- Retention in Layered Snowcovers, Defence Science Journal, 45 (2), 79-91, 1995. 
Kojima, K., Densification of seasonal snow cover, in Physics of Ice and Snow, Proc. Int. Conf. on Low Temperature Science, pp. 929-952, Inst. of Low Temperature Science, Hokkaido Univ., Sapporo, Japan, 1967.

Koster, R.D., and M. Suarez, Energy and water balance calculations in the Mosaic LSM, pp. 59, NASA Tech. Memo, 1996.

Koster, R.D., and M.J. Suarez, A Comparative-Analysis of 2 Land Surface Heterogeneity Representations, Journal of Climate, 5 (12), 1379-1390, 1992.

Koster, R.D., M.J. Suarez, A. Ducharne, M. Stieglitz, and P. Kumar, A catchment-based approach to modeling land surface processes in a GCM. Part I: Model structure, $J G R$, in review.

Kripalani, R.H., S. S.V., A.D. Vernekar, and V. Thapliyal, Empirical study on Nimbus-7 snow mass and Indian summer monsoon rainfall, Inter. J. Clim, 16, 23-34, 1996.

Kumar, K.K., B. Rajagopalan, and M.A. Cane, On the weakening relationship between the Indian monsoon and ENSO, Science, 284 (5423), 2156-2159, 1999.

LDEO, climate data library, 2000.

Levine, E.R., and R.G. Knox, Modeling soil temperature and snow dynamics in northern forests, Journal of Geophysical Research-Atmospheres, 102 (D24), 29407-29416, 1997.

Liston, G.E., Seasonal snowcover of the foothills region of Alaska's arctic slope: A survey of properties and processes, M.S. thesis, University of Alaska, Fairbanks, 1986. 
Liston, G.E., and M. Sturm, A snow-transport model for complex terrain, Journal of Glaciology, 44 (148), 498-516, 1998.

Loth, B., and H.F. Graf, Modeling the snow cover in climate studies - 1. Long-term integrations under different climatic conditions using a multilayered snow-cover model, Journal of Geophysical Research-Atmospheres, 103 (D10), 11313-11327, 1998a.

Loth, B., and H.F. Graf, Modeling the snow cover in climate studies - 2. The sensitivity to internal snow parameters and interface processes, Journal of Geophysical Research-Atmospheres, 103 (D10), 11329-11340, 1998b.

Loth, B., H.F. Graf, and J.M. Oberhuber, Snow Cover Model For Global Climate Simulations, Journal of Geophysical Research-Atmospheres, 98 (D6), 1045110464, 1993.

Lynch-Stieglitz, M., The Development and Validation of a Simple Snow Model For the Giss GCM, Journal of Climate, 7 (12), 1842-1855, 1994.

Mysak, L.A., and S.A. Venegas, Decadal climate oscillations in the Arctic: A new feedback loop for atmosphere-ice-ocean interactions, Geophysical Research Letters, 25 (19), 3607-3610, 1998.

NSIDC, Northern Hemisphere EASE-Grid Weekly Snow Cover and Sea Ice Extent, pp. Volumes 1.0-2.0, 1996.

Oechel, W.C., G. Vourlitis, and S.J. Hastings, Cold season CO2 emission from arctic soils, Global Biogeochemical Cycles, 11 (2), 163-172, 1997. 
Pauwels, V.R.N., and E.F. Wood, A soil-vegetation-atmosphere transfer scheme for the modeling of water and energy balance processes in high latitudes 2. Application and validation, Journal of Geophysical Research-Atmospheres, 104 (D22), 27823-27839, 1999.

Pitman, A.J., Z.-L. Yang, J.G. Cogley, and A.Henderson-Sellers, Description of bare essentials of surface transfer for the bureau of meterological research centre AGCM, BMRC, Australia, 1991.

Ropelewski, C.F., A. Robock, and M. Matson, Comments on "An apparent relationship between the Eurasian snow cover and Indian monsoon rainfall, J. Clim. Appl. Meteor, 23, 341-342, 1984.

Sellers, P.J., B.W. Meeson, J. Closs, J. Collatz, F. Corprew, D. Dazlich, F.G. Hall, Y. Kerr, R. Koster, S. Los, K. Mitchell, J. McManus, D. Myers, K.J. Sun, and P. Try, The ISLSCP initiative I global datasets: Surface boundary conditions and atmospheric forcings for land-atmosphere studies, Bulletin of the American Meteorological Society, 77 (9), 1987-2005, 1996.

Sivapalan, M., K. Beven, and E.F. Wood, On hydrologic similarity. 2. A scaled model of storm runoff production., Water Resources Research, 23, 2266-2278, 1987.

Slater, A.G., A.J. Pitman, and C.E. Desborough, The validation of a snow parameterization designed for use in general circulation models, International Journal of Climatology, 18 (6), 595-617, 1998.

Stieglitz, M., A. Giblin, J. Hobbie, G. Kling, and M. Williams, Simulating the effects of climate change and climate variability on carbon dynamics in Arctic tundra, Global Biogeochemical Cycles, in review. 
Stieglitz, M., J. Hobbie, A. Giblin, and G. Kling, Hydrologic modeling of an arctic tundra watershed: Toward Pan- Arctic predictions, Journal of Geophysical ResearchAtmospheres, 104 (D22), 27507-27518, 1999.

Stieglitz, M., D. Rind, J. Famiglietti, and C. Rosenzweig, An efficient approach to modeling the topographic control of surface hydrology for regional and global climate modeling, Journal of Climate, 10 (1), 118-137, 1997.

Verdin, K.L., and J.P. Verdin, A topological system for delineation and codification of the Earth's river basins, Journal of Hydrology, 218 (1-2), 1-12, 1999.

Verseghy, D.L., Class-a Canadian Land Surface Scheme For Gcms .1. Soil Model, International Journal of Climatology, 11 (2), 111-133, 1991.

Wood, E.F., D.P. Lettenmaier, X. Liang, D. Lohmann, A. Boone, S. Chang, F. Chen, Y.J. Dai, R.E. Dickinson, Q.Y. Duan, M. Ek, Y.M. Gusev, F. Habets, P. Irannejad, R. Koster, K.E. Mitchel, O.N. Nasonova, J. Noilhan, J. Schaake, A. Schlosser, Y.P. Shao, A.B. Shmakin, D. Verseghy, K. Warrach, P. Wetzel, Y.K. Xue, Z.L. Yang, and Q.C. Zeng, The Project for Intercomparison of Land-surface Parameterization Schemes (PILPS) phase 2(c) Red-Arkansas River basin experiment: 1. Experiment description and summary intercomparisons, Global and Planetary Change, $19(1-4), 115-135,1998$.

Yang, Z.L., R.E. Dickinson, A. Robock, and K.Y. Vinnikov, Validation of the snow submodel of the biosphere-atmosphere transfer scheme with Russian snow cover and meteorological observational data, Journal of Climate, 10 (2), 353-373, 1997. 
Zhang, T., R.G. Barry, and K. Knowles, Statistics and characteristics of permafrost and ground ice distribution in the Northern Hemisphere, Polar Geography, 22 (2), 147-169, 1999.

Zimov, S.A., S.P. Davidov, Y.V. Voropaev, S.F. Prosiannikov, I.P. Semiletov, M.C. Chapin, and F.S. Chapin, Siberian $\mathrm{CO} 2$ efflux in winter as a $\mathrm{CO} 2$ source and cause of seasonality in atmospheric $\mathrm{CO}$, Climatic Change, 33 (1), 111-120, 1996.

Zimov, S.A., I.P. Semiletov, S.P. Daviodov, Y.V. Voropaev, S.F. Prosyannikov, C.S. Wong, and Y.H. Chan, Wintertime $\mathrm{CO}_{2}$ Emission From Soils of Northeastern Siberia, Arctic, 46 (3), 197-204, 1993. 


\section{Figure Captions List}

Figure 1: Surface ground temperature, overlying air temperature, and snow cover at two sites with significant snow cover. (a) The Sleepers River NOAA-ARS snow research station located in the Eastern Highlands of Vermont. (b) The Imnavait Creek watershed located in the foothills of the Brooks Range on the North Slope of Alaska.

Figure 2: (a) Hourly surface radiating temperature for 20 days starting 1 January 1971 at the NOAA-ARS research station (stars) and the LSM without snow insulation (solid line) [Lynch-Stieglitz, 1994]. (b) Hourly surface radiating temperature for 20 days starting 1 January 1971 at the NOAA-ARS research station (stars) and an LSM using the three-layer snow model of LynchStieglitz [1994] (solid line).

Figure 3: (a) Measured hourly surface radiating temperature for 20 days starting 1 January 1971 at the NOAA-ARS research station (stars) and predicted by an LSM with the three layer snow model of (solid line) [Lynch-Stieglitz, 1994].

(b) Measured snow depth, water equivalent snow depth, and snowpack density for 1971 - 1972 at the NOAA-ARS research station (stars) and predicted by an LSM with the three-layer snow model of (solid line) [LynchStieglitz, 1994].

Figure 4: The spatial evolution of snow coverage over the approximately 5000 catchments comprising North America for the 1987-1988 snow season. 
Figure 5: The fractional snow coverage over North America for the period 1 January 1997 through 31 December 1998 for both the old and new snow scheme as well as coverage determined from satellite (NOAA/NESDIS weekly snow coverage, found on the ISLSCP CD-ROM or the LDEO Climate data library [2000]) and from ground stations (Air Force climatological data set, [Foster Jr. and Davy, December, 1988]).

Figure 6: The evolution of ground temperatures at depth for the 1987-1988 snow season at $55 \mathrm{~N}, 99 \mathrm{~W}$. The presence or absence of snow in the new model is indicated by the white region labeled "snow". The presence or absence of snow in the old model is indicated by the stippled region. A layer that is both white and stippled indicates the presence of snow cover in both the new and old snow model. STW refers to the uppermost soil layer.

Figure 7: The evolution of ground temperatures at depth for the 1987-1988 snow season at $61 \mathrm{~N}, 99 \mathrm{~W}$. The presence or absence of snow in the new model is indicated by the white region labeled "snow". The presence or absence of snow in the old model is indicated by the stippled region. A layer that is both white and stippled indicates the presence of snow cover in both the new and old snow model. STW refers to the uppermost soil layer.

Figure 8: The evolution of ground temperatures at depth for the 1987-1988 snow season at $68 \mathrm{~N}, 159 \mathrm{~W}$. The presence or absence of snow in the new model is indicated by the white region labeled "snow". The presence or absence of snow in the old model is indicated by the stippled region. A layer that is both 
white and stippled indicates the presence of snow cover in both the new and old snow model. STW refers to the uppermost soil layer.

Figure 9: The spatial difference in temperatures for the deepest soil layer between the new and old snow scheme after the ten year spin up.

Figure 10: Model-generated and observed (NSIDC digital permafrost maps, [Zhang et al., 1999]) permafrost regions. A catchment is considered to be within a permafrost region and thereby shaded gray if the deepest model layer within that catchment is frozen throughout the $1987-1988$ simulation period. The solid line refers to the observed permafrost line corresponding to $50 \%$ permafrost coverage whereas the dashed line corresponds to $10 \%$ permafrost coverage. With few exceptions, the permafrost boundary generated by the new scheme appears highly accurate. 


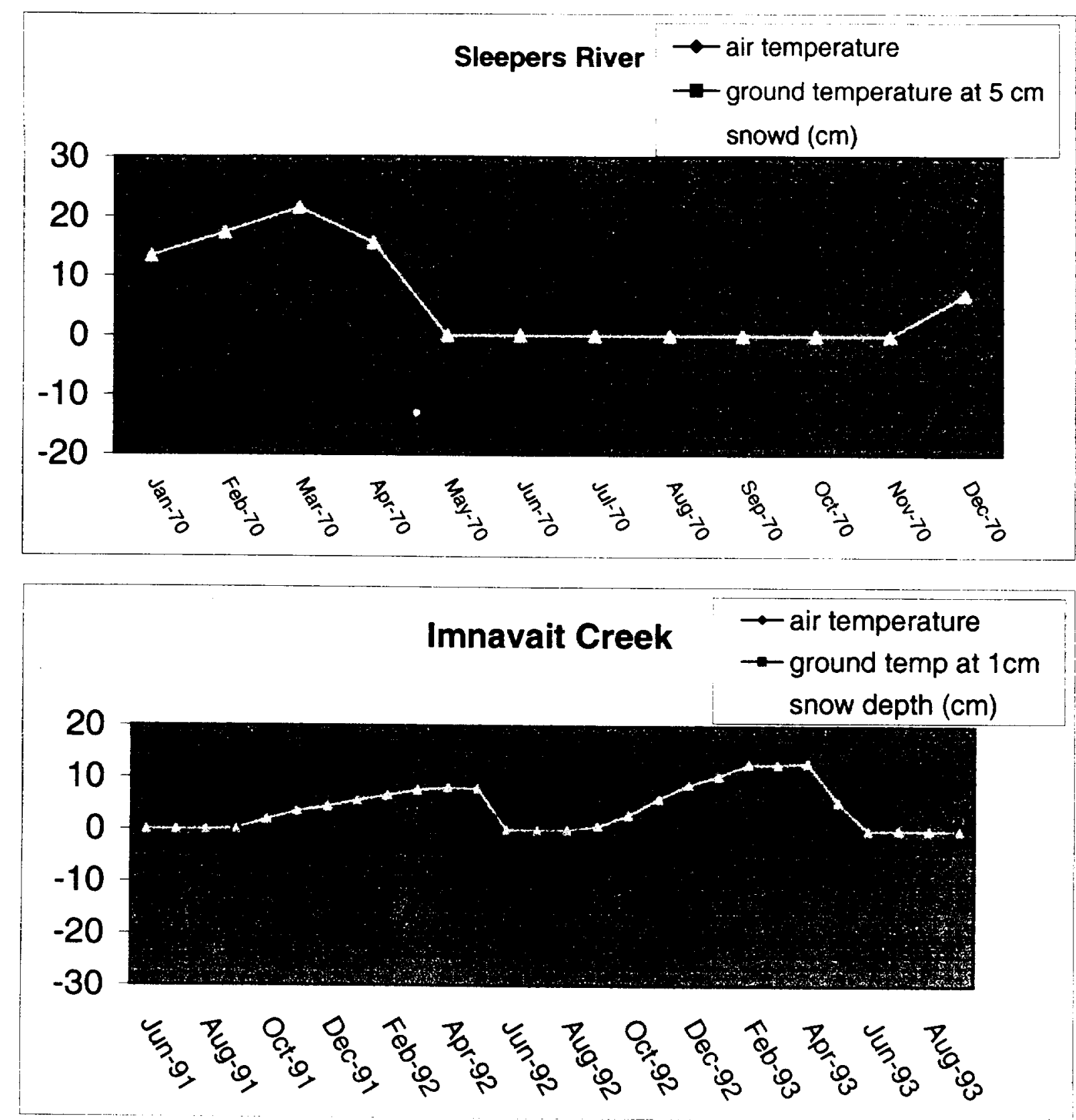




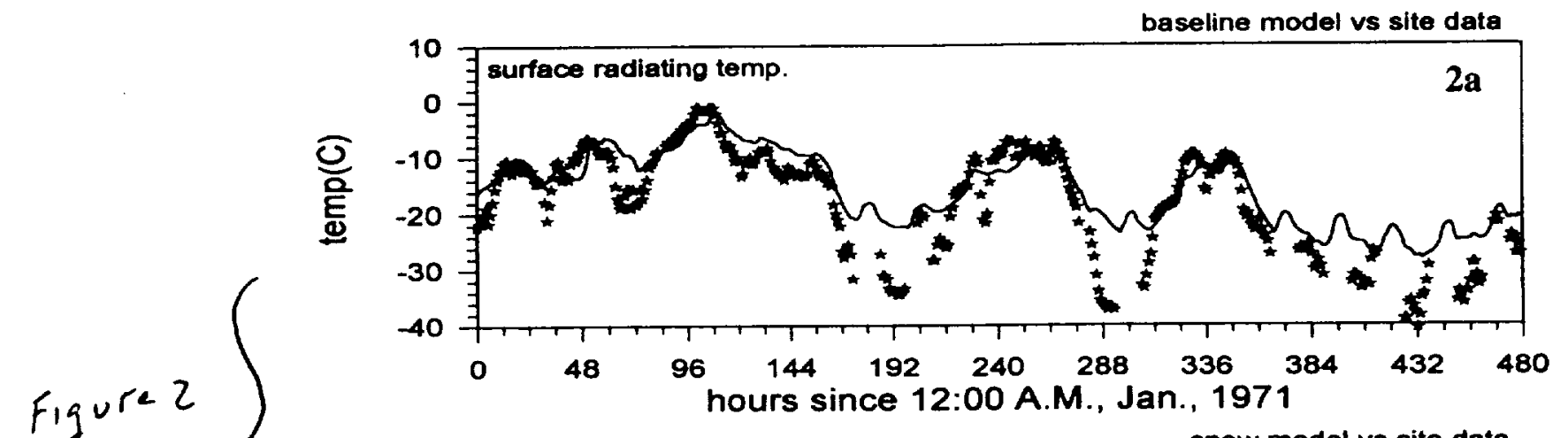
Figure 2
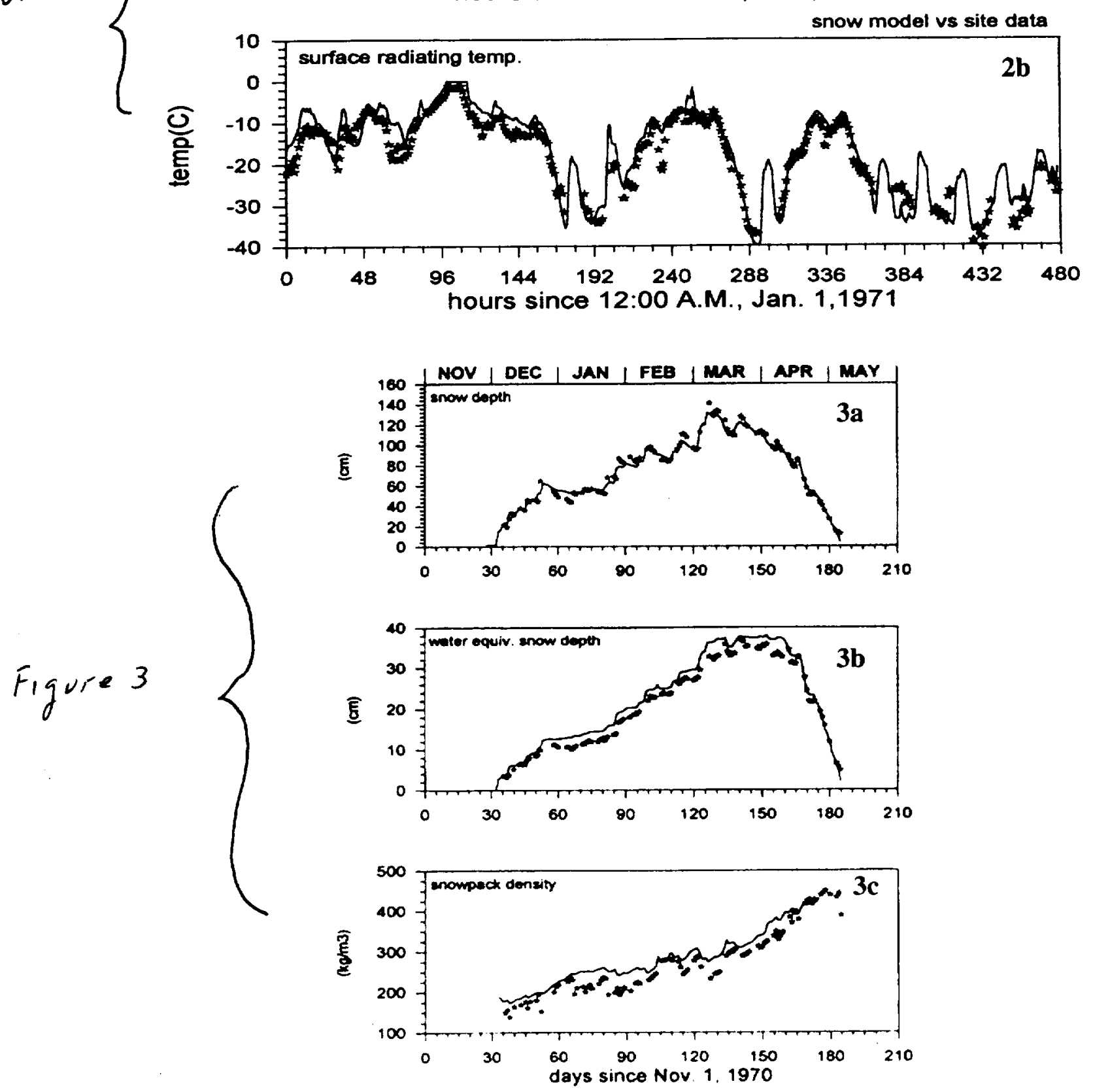
Observations
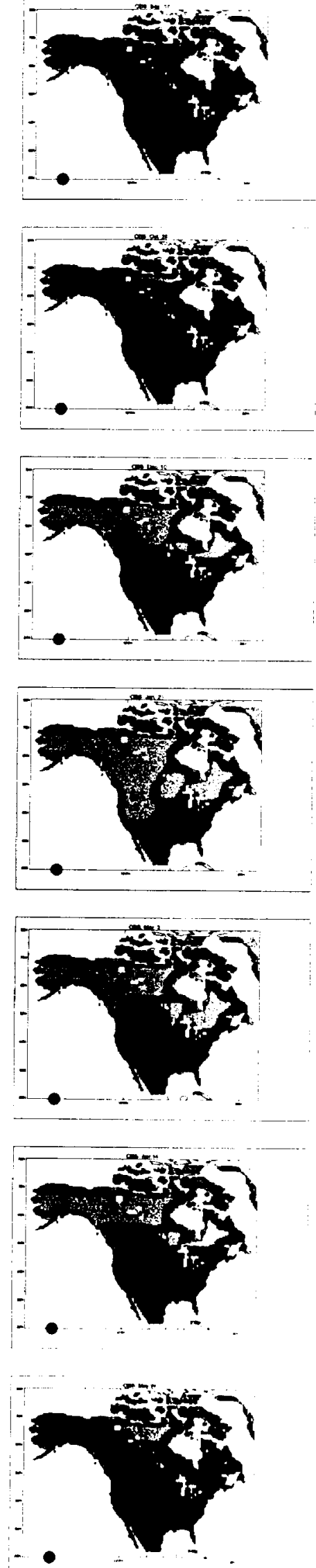

New Model
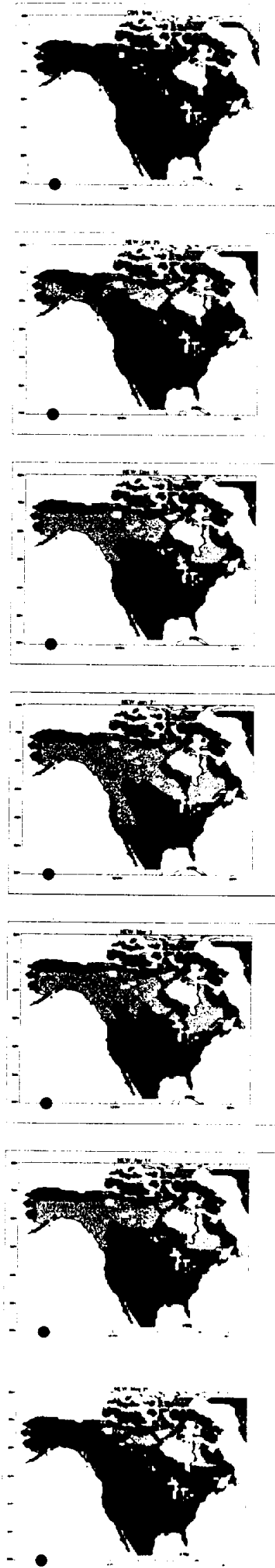

Old Model

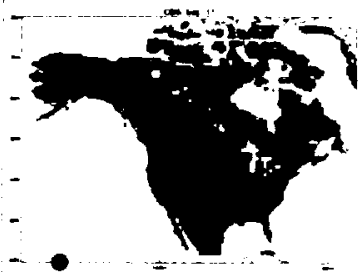

Sept. 17

Oct. 29

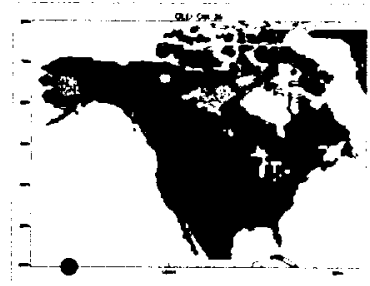

Dec. 10

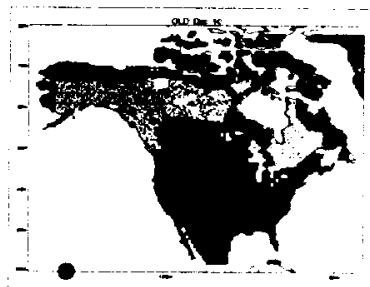

Jan. 21
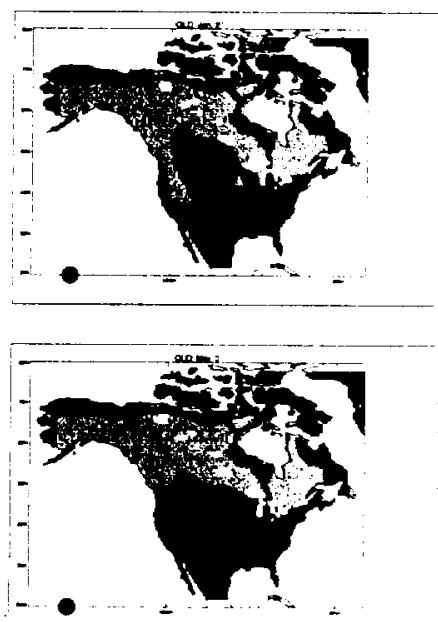

Mar. 3

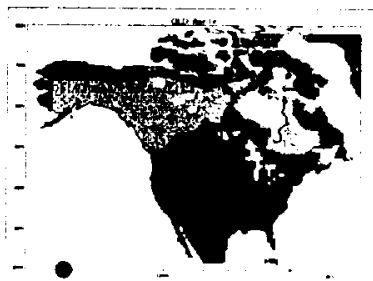

Apr. 14

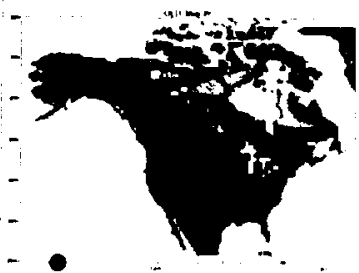

May 26 


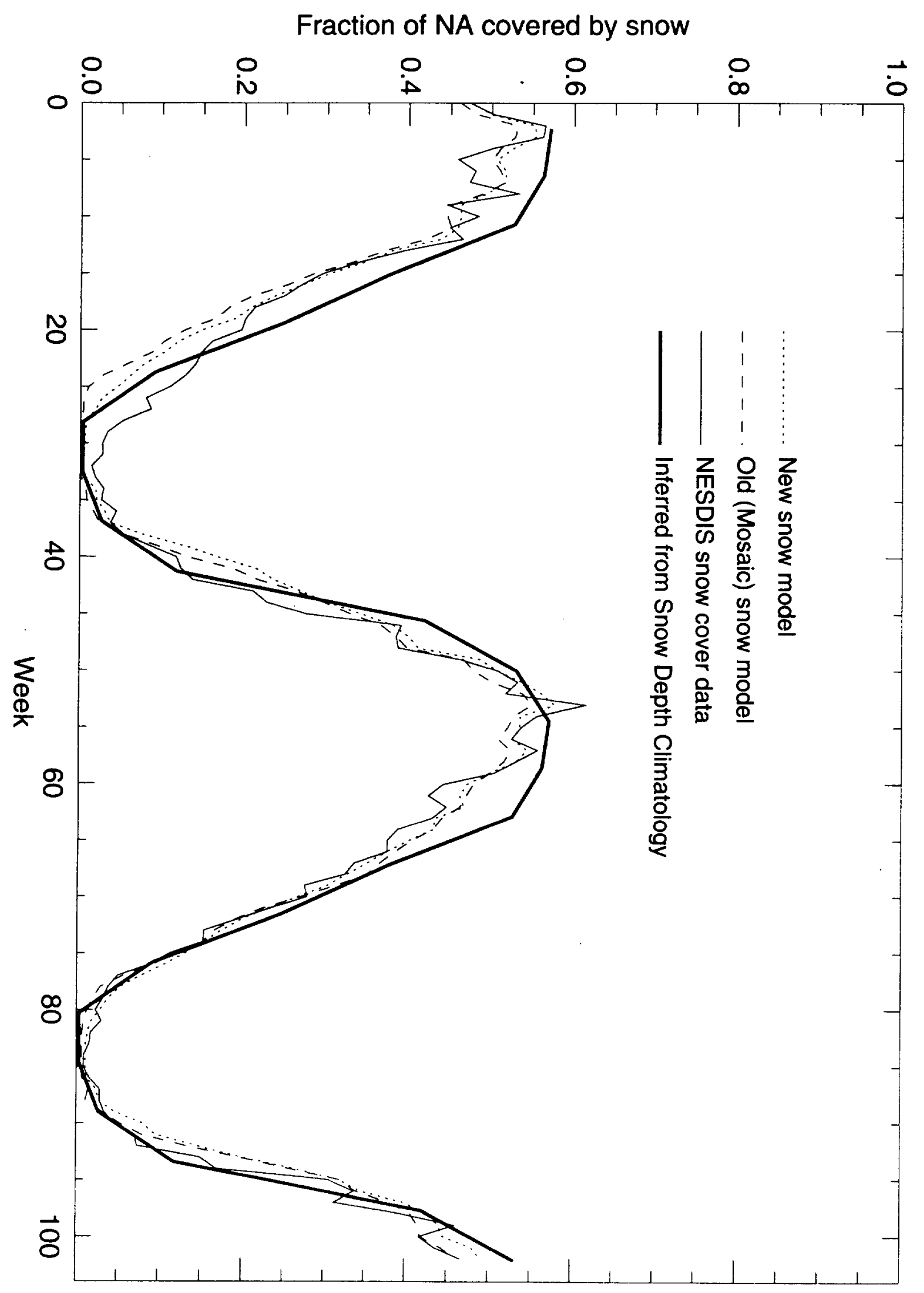



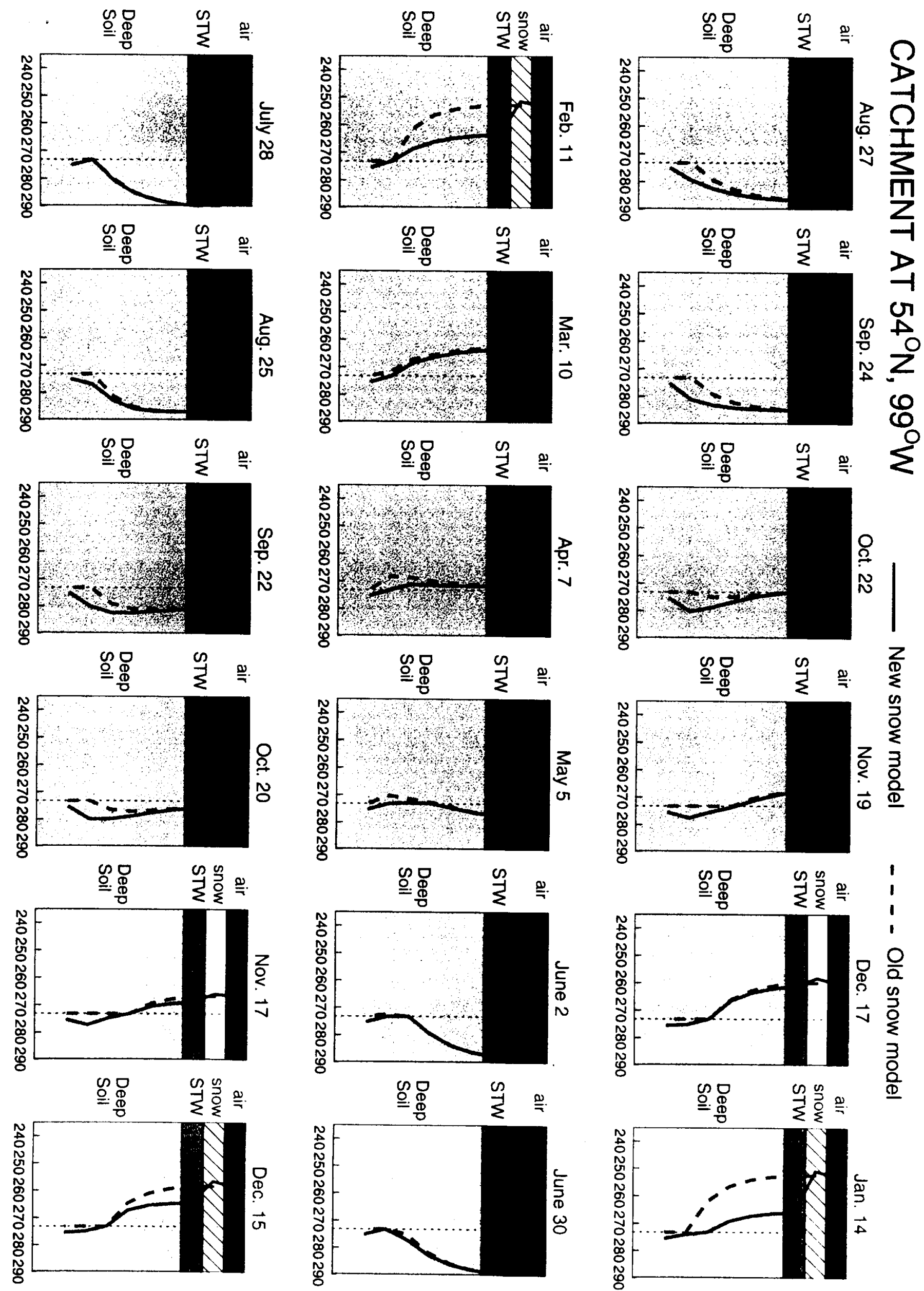

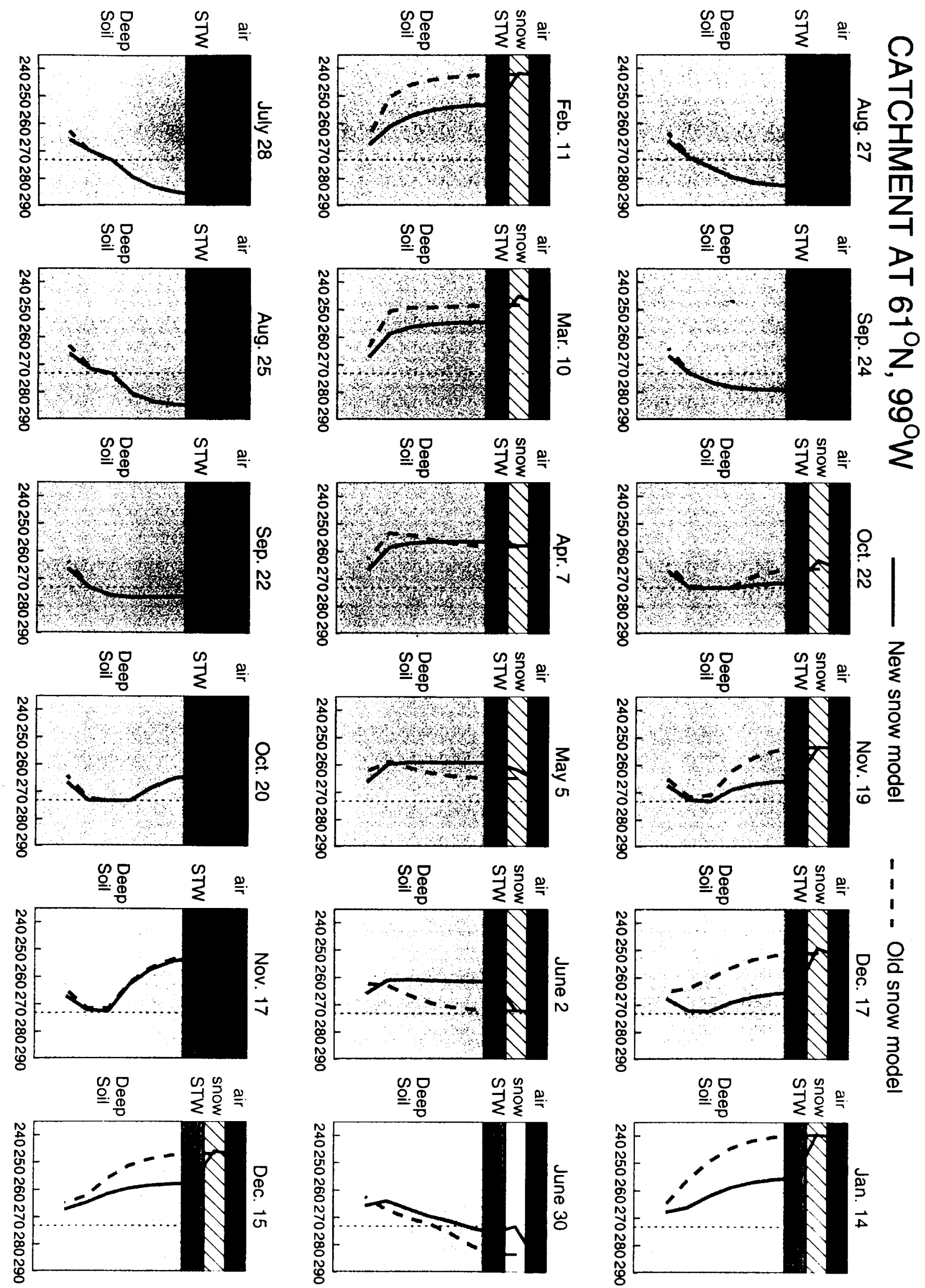

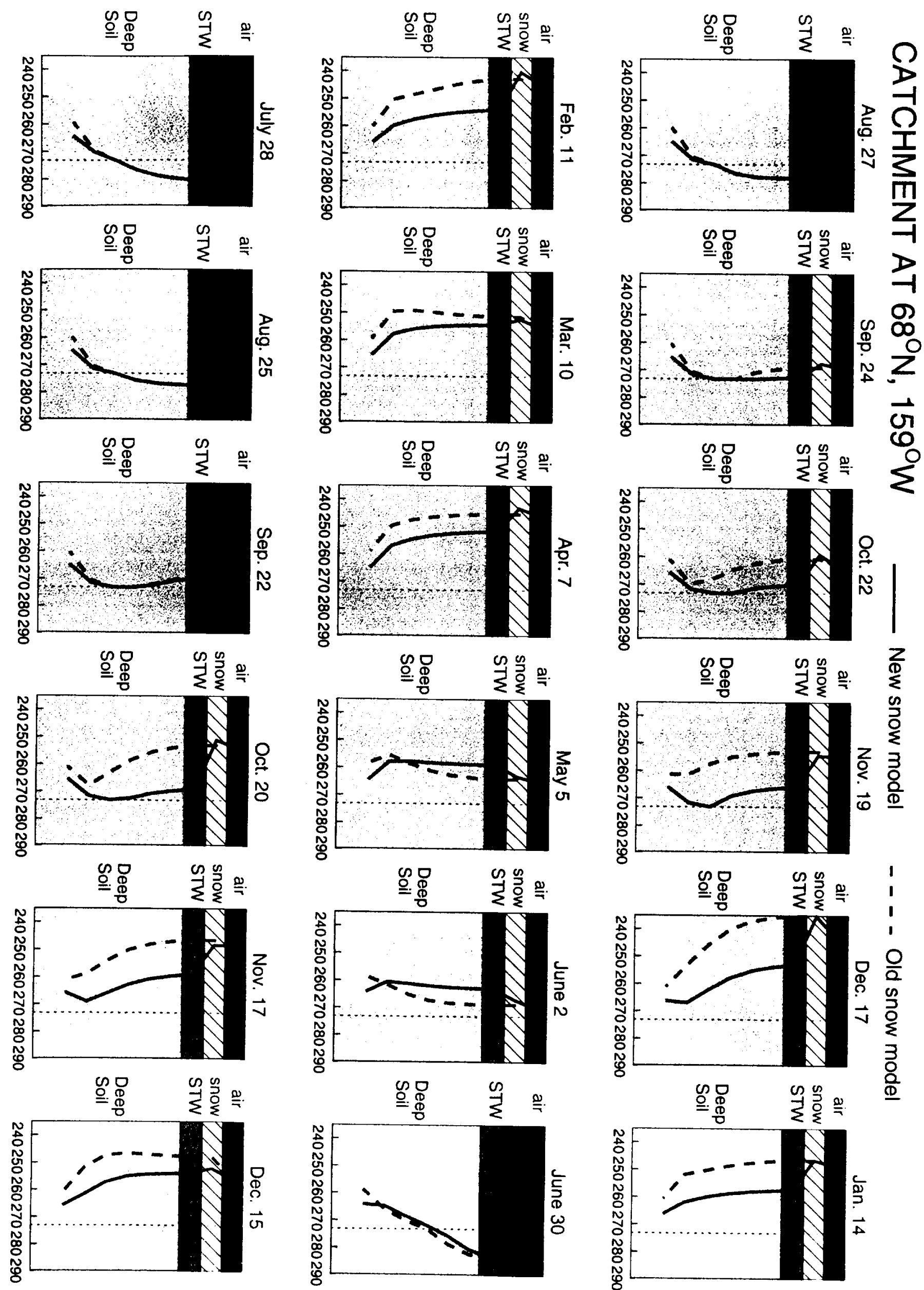

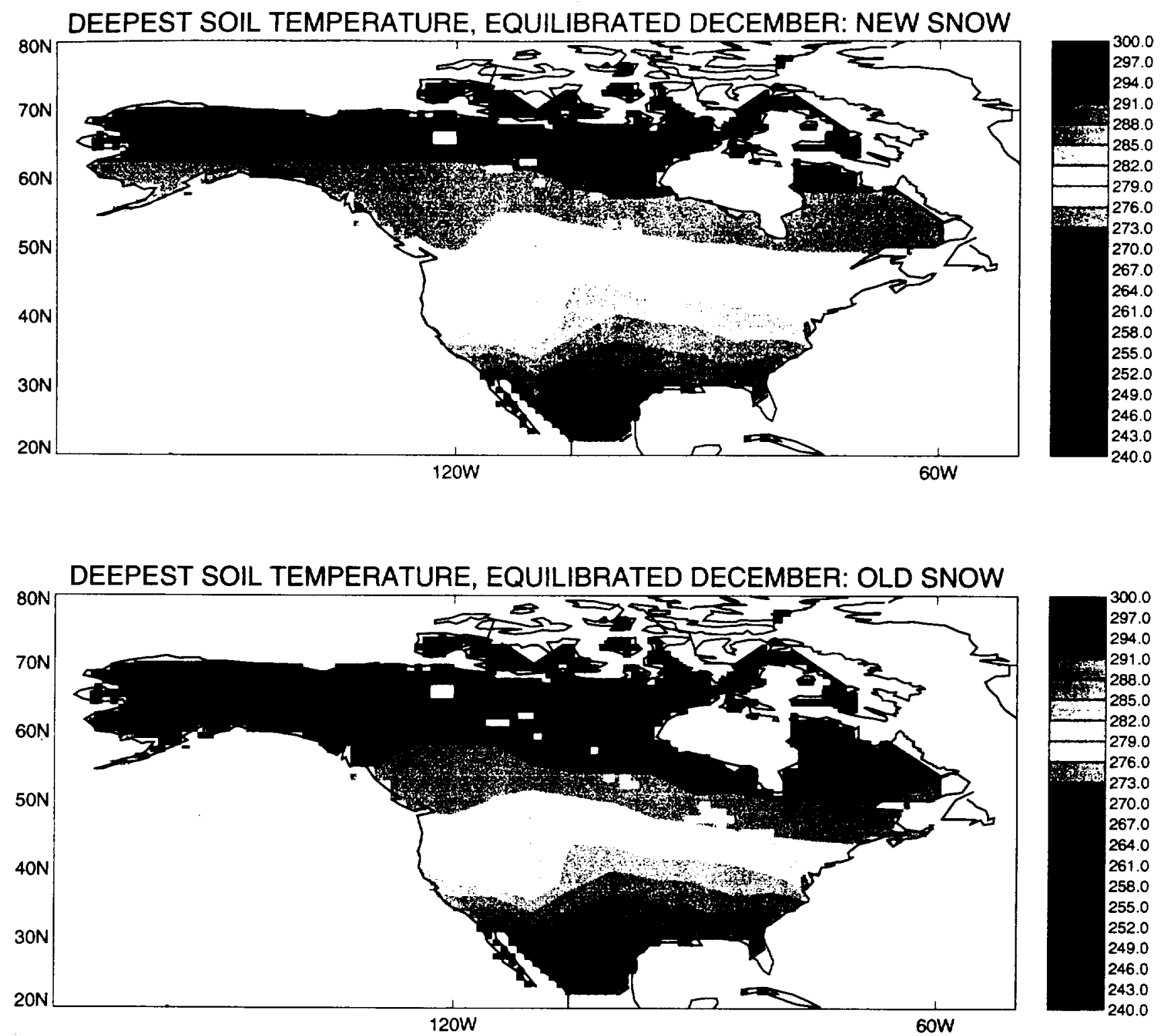

TEMPERATURE DIFFERENCE: NEW MINUS OLD

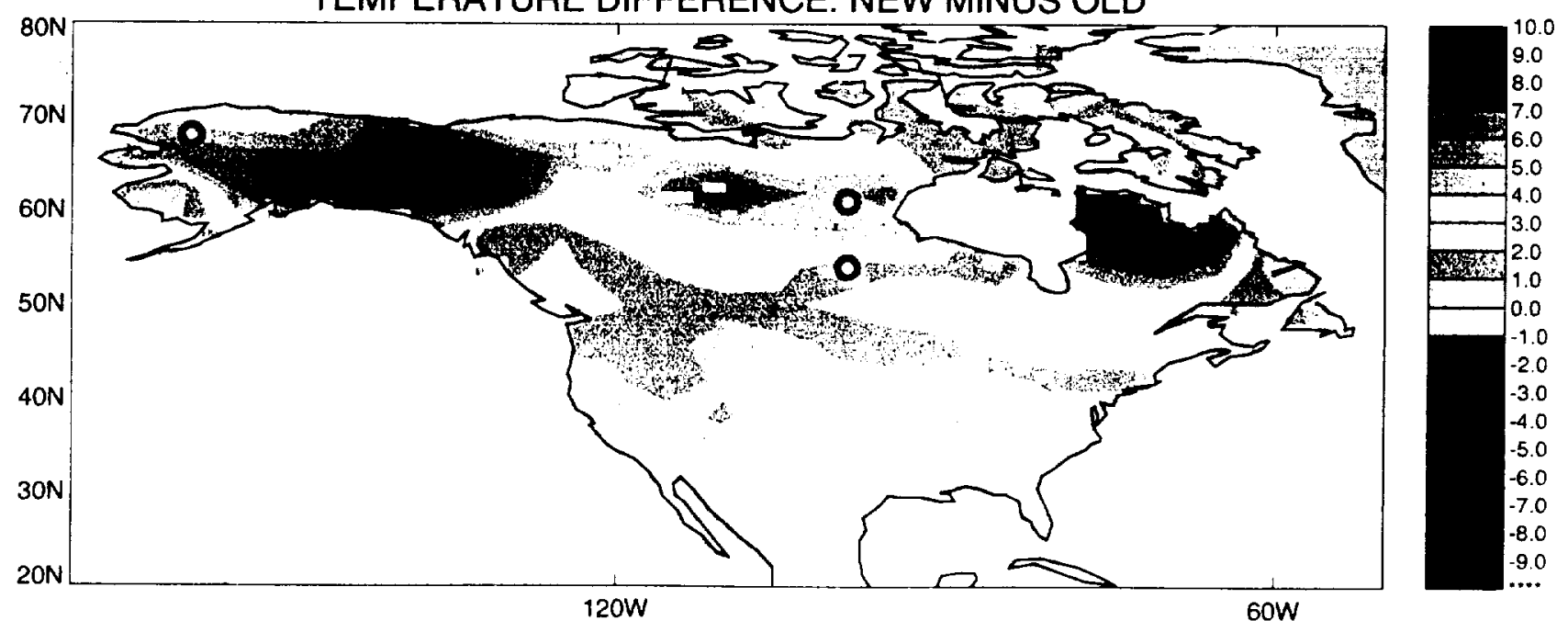


PERMAFROST: NEW MODEL
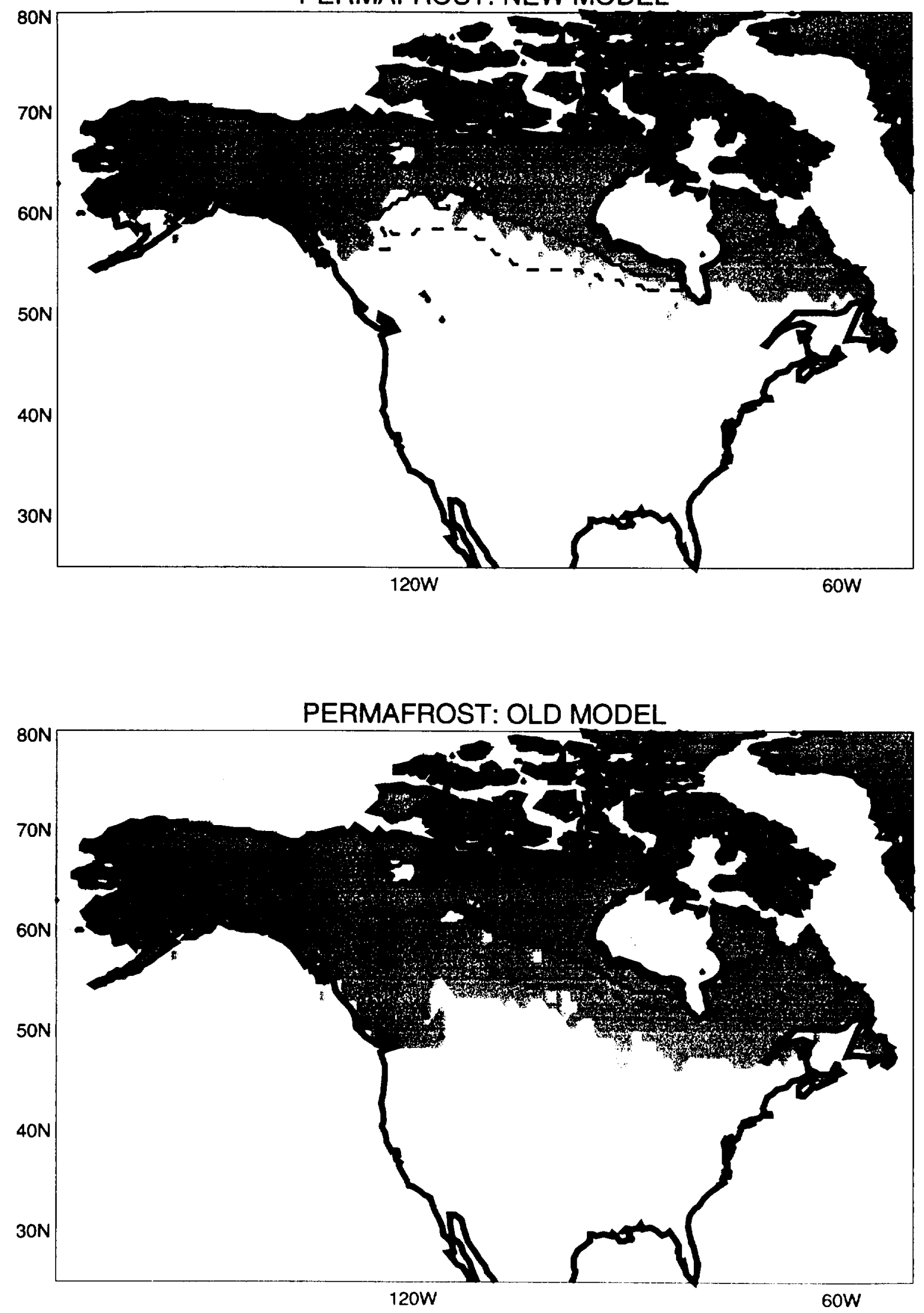